\title{
Growth regulators and darkness increase efficiency in in vitro culture of immature embryos from peppers
}

\author{
Juan Pablo Manzur, María de las Nieves Calvache-Asensio, Adrian Rodriguez-Burruezo*
}

Polytechnic University of Valencia/Institute for Conservation \& Improvement of Valentian Agrodiversity, Camino de Vera, $\mathrm{s} / \mathrm{n}-46022$ - Valencia - Spain.

*Corresponding author <adrodbur@upvnet.upv.es>

Edited by: Antonio Costa de Oliveira
ABSTRACT: Common pepper (Capsicum annuum L.) is one of the most important vegetables in the world, and extensive breeding efforts are being made to develop new improved strains of this species. In this regard, in vitro culture of immature embryos may help breeders accelerate breeding cycles and overcome interspecific barriers, among other applications. In this study, we have optimized a protocol for in vitro culture of immature embryos of $C$. annuum. Levels of indole-3-acetic acid (IAA) and zeatin have been tested to improve the efficiency (germination rates) of this technique in $C$. annuum embryos at the four main immature stages (i.e. globular, heart, torpedo, and early cotyledonary) from four varietal types of this species (California Wonder, Piquillo, Guindilla, and Bola). The effect of 5-day initial incubation in the dark was also tested on the most efficient hormone formulation. On average, relatively low levels of both IAA and zeatin (0.01 $\mathrm{mg} \mathrm{L}^{-1}$ each) $\left(\mathrm{M}_{1}\right)$ provided the highest germination rates, particularly in the advanced stages (torpedo and cotyledonary). To a lesser extent, the lack of these growth regulators $\left(\mathrm{M}_{0}\right)$ or high IAA (0.2 $\left.\mathrm{mg} \mathrm{L}^{-1}\right) /$ low zeatin $\left(0.01 \mathrm{mg} \mathrm{L}^{-1}\right)\left(\mathrm{M}_{2}\right)$ combination also had a positive response. On the contrary, high zeatin levels $\left(0.2 \mathrm{mg} \mathrm{L}^{-1}\right)$ produced very low germination rates or callus development (efficiency 0-7 \%). Different responses were also found between genotypes. Thus, considering the best media $\left(M_{0}, M_{1}, M_{2}\right)$, Bola embryos had the highest rates. $M_{1}$ plus 5 -days of initial dark incubation ( $\mathrm{M}_{1}$-D) improved the efficiency rates at all embryo stages, particularly in the earliest (globular) embryos which increased from $3 \%$ to $>20 \%$.

Keywords: Capsicum peppers, embryo stage, genotypic diversity, indole-3-acetic acid, zeatin and Murashige-Skoog salts (MS) considerably increase the efficiency of embryo germination in most Capsicum genotypes and embryo stages, including globular embryos (Manzur et al., 2010, 2013).

The role of factors like growth regulators or darkness has still not been studied. In this respect, low levels of gibberellic acid $\left(\mathrm{GA}_{3}\right)$ promote embryo growth in several species (Moshkov et al., 2008) and replace the role of the suspensor, which is lost during excision (Haslam and Yeung, 2011; Monnier, 1995). Additionally, auxins (usually indole-3-acetic acid, IAA) may promote the growth of primary roots, hypocotyls and cotyledons when administered in low doses (Machakova et al., 2008), while cytokinins usually show favorable effects on early stages at high levels (Raghavan, 2006). Furthermore, combinations of auxins and cytokinins have showed favorable effects on early embryos (Salamma and Ravi Prasad Rao, 2013). Moreover, initial dark incubation improved germination rates and embryo growth in several species (Razdan, 2003). The response to these factors is highly dependent on the species (Monnier, 1995) and, therefore, our main objective was to assess the effect of IAA, zeatin and dark incubation on $C$. annuum immature embryos. This study provides useful information for the optimization of in vitro culture protocols in immature embryos of peppers.

\section{Materials and Methods}

Plant material and growing conditions

A total of four accessions from $C$. annuum were 
utilized (Table 1). Plants were transplanted to a glasshouse in Valencia (39 29'00" N, 0²0'28" W) (Spain) in Feb 2011 and grown during the spring-summer season. Natural illumination and a temperature range of $18 / 25{ }^{\circ} \mathrm{C}$ were used for this experiment. Plants were drip irrigated every $8 \mathrm{~h}$ for $3 \mathrm{~min}$. $\left(4 \mathrm{~L} \mathrm{~h}^{-1}\right)$ and fertilizer was applied with irrigation water at a rate of $1 \mathrm{~g}$ $\mathrm{L}^{-1}$ in the form of the commercial fertilizer $15 \mathrm{~N}-2.2 \mathrm{P}$ $24.9 \mathrm{~K}$

\section{Evaluated media and conditions}

To study the role of auxins and cytokinins a formulation previously optimized by Manzur et al. (2013), consisting of $1 /{ }_{2} \mathrm{MS}$ dose $\left(2.2 \mathrm{~g} \mathrm{~L}^{-1}\right.$ of commercial formulation), sucrose at $40 \mathrm{~g} \mathrm{~L}^{-1}$, gibberellic acid $\left(\mathrm{GA}_{3}\right)$ at $0.01 \mathrm{mg} \mathrm{L}^{-1}$, agar at $7 \mathrm{~g} \mathrm{~L}^{-1}$, and $\mathrm{pH} 5.7$ was utilized as control $\left(\mathrm{M}_{0}\right)$. Then, on the basis of $\mathrm{M}_{0}$, relatively low (0.01 $\left.\mathrm{mg} \mathrm{L}^{-1}\right)$ and/or high (0.2 $\left.\mathrm{mg} \mathrm{L}^{-1}\right)$ levels of IAA and zeatin were combined to assess the effect of these growth regulators, while $\mathrm{GA}_{3}$ at $0.01 \mathrm{mg} \mathrm{L}^{-1}$ was kept in all formulations as we considered it essential for re- placing the suspensor (Kawashima and Goldberg, 2009; Moshkov et al., 2008). As a result, the formulations studied were as follows: $M_{0}$ or control, which lacked both IAA and zeatin, $\mathrm{M}_{1} / 0.01 \mathrm{mg} \mathrm{L}^{-1} \mathrm{IAA}$ and $0.01 \mathrm{mg}$ $\mathrm{L}^{-1}$ zeatin), $\mathrm{M}_{2}$ (0.2 $\mathrm{mg} \mathrm{L}^{-1}$ IAA and $0.01 \mathrm{mg} \mathrm{L}^{-1}$ zeatin), $\mathrm{M}_{3}\left(0.01 \mathrm{mg} \mathrm{L}^{-1} \mathrm{IAA}\right.$ and $0.2 \mathrm{mg} \mathrm{L}^{-1}$ zeatin) and $\mathrm{M}_{4}(0.2$ $\mathrm{mg} \mathrm{L}{ }^{-1}$ IAA and $0.2 \mathrm{mg} \mathrm{L}^{-1}$ zeatin). Finally, once the best IAA/zeatin combination had been established, the effect of darkness was tested on embryo cultures in accordance with this formulation plus 5 days of initial incubation in darkness. The medium without hormones was sterilized by autoclave $\left(121^{\circ} \mathrm{C}\right.$ for $\left.20 \mathrm{~min}\right)$, while hormones were sterilized separately by microfiltration $(0.20 \mu \mathrm{m}$ filters) to avoid denaturation and, then, added to the warm $\left(35-40{ }^{\circ} \mathrm{C}\right)$ autoclaved media before solidifying.

\section{Isolation and in vitro culture of embryos}

To achieve the required number of immature seeds for the experiment, plants were self-pollinated repeatedly beginning Apr 2011 (Figure 1A). Subse-

Table 1 - Origin and fruit traits of the accessions utilized in the present experiment.

\begin{tabular}{|c|c|c|c|c|c|c|}
\hline Accession & Abbreviation & Origin & Color & Weight & Length & Width \\
\hline & & & & g & 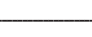 & - \\
\hline California Wonder & California & Breeding line. UPV-COMAV germplasm bank & Pale red & $90-150$ & $8-11$ & $6-10$ \\
\hline Guindilla de Ibarra & Guindilla & Neiker. Ibarra. Spain & Deep red & $7-12$ & $7-12$ & $1-2$ \\
\hline Pimiento de Bola & Bola & Cons. Reg. DOP Pimentón Murcia. Murcia. Spain & Red & $10-14$ & $3-5$ & $4-6$ \\
\hline
\end{tabular}

A
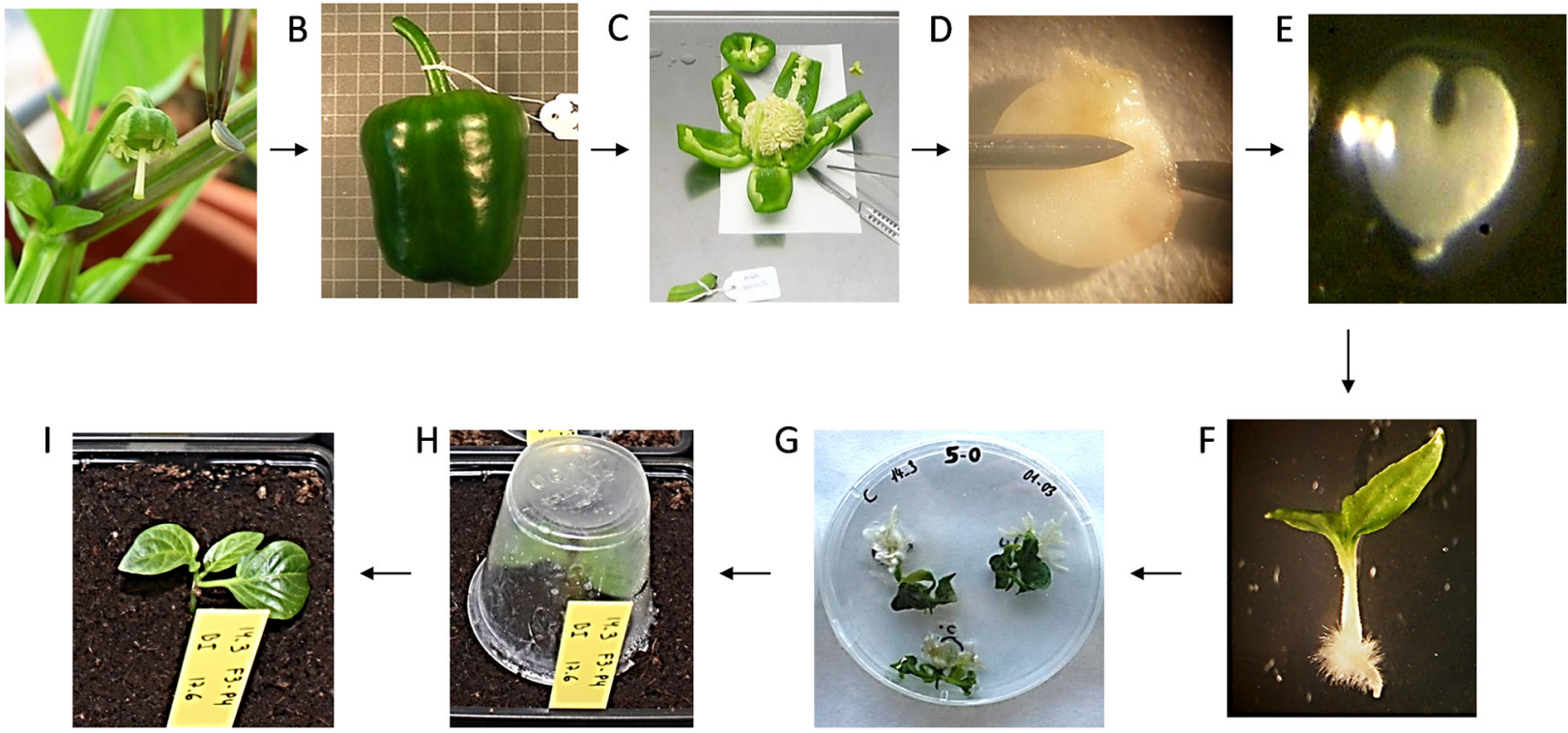

Figure 1 - Diagram of the in vitro culture technique in California Wonder embryos: A) self-pollination, B) immature fruit just harvested opening, C) fruit and seed sterilization, D-E) embryo excision, stage identification and in vitro sowing, F) embryo development and germination, G) plantlet evaluation and $\mathrm{H}-\mathrm{I}$ ) acclimation. 
quently, fruits were harvested 15-30 days after pollination (DAP) (Figure 1B). Once in the lab, the whole fruit was surface-sterilized with ethanol (96\%) under laminar flow cabinet conditions. Then, immature seeds were removed (Figure $1 \mathrm{C}$ ) and dissected under stereomicroscope $(\times 24)$, using hypodermic sterilized needles (Figure 1D). Embryos were excised carefully, recording the embryo stage, and immediately cultured in $90 \times 15$ $\mathrm{mm}$ Petri dishes containing the corresponding medium (Figure 1E). These Petri dishes were then sealed with self-sealing film and incubated in a growth chamber $(25$ $\pm 1{ }^{\circ} \mathrm{C} ; 70 \% \mathrm{HR} ; 16 \mathrm{~h} / 8 \mathrm{~h}$; light/dark). The only exception corresponded to the dark-incubated embryos. In this case the Petri dishes were wrapped with aluminum foil for five days.

The efficiency of in vitro culture was evaluated in terms of the percentage of embryos which evolved to plantlets by showing an early development of root and shoot (Figure 1F-G) and, subsequently, a satisfactory response to acclimatization (Figure $1 \mathrm{H}-\mathrm{I}$ ), which has been found to be correlated with normal development in the adult stage (Manzur et al., 2013). Embryos or plantlets with abnormalities or callus development were considered not germinated and/or not viable.

\section{Experimental design and statistical analysis}

The experimental design was set up as a complete factorial design $(4 \times 4 \times 6)$ with five replicates, including four accessions, four embryo developmental stages (globular, heart, torpedo and cotyledonary), and six in vitro media/conditions $\left(M_{0}, M_{1}, M_{2}, M_{3}, M_{4}\right.$, and $M_{1}$ plus 5 days of initial dark incubation $=M_{1}-$ D). Each replicate consisted of one Petri dish with three embryos each. Thus, 15 embryos were cultured for each accession $\times$ stage $\times$ media/condition combination and, therefore, the present experiment required the excision, in vitro culture, and evaluation of a total of 1,440 embryos. Data of in vitro culture efficiency (percentage) were subjected to analysis of variance to assess differences between means. Since original data were recorded as a percentage, they were transformed by arcsine square root. Transformed data were then tested, but differences between the results obtained with transformed and non-transformed data were negligible. Therefore, the ANOVA presented in this work was performed on the original non-transformed data.

\section{Results and Discussion}

\section{Effect of growth regulators}

On average, the more advanced the embryo, the higher the germination rate. Mean germination rates ranged from $2 \%$ in globular embryos to $28 \%$ in cotyledonary (Table 2). In this regard, embryos are highly dependent in terms of nutrition and draw upon the endosperm, the suspensor and the surrounding maternal tissues during the early development phases (heterotrophic phase), while, later, they are metabolically
Table 2 - Culture efficiency (\% germination) of immature $C$. annuum embryos depending on the in vitro medium $\left(\mathrm{M}_{0}\right.$ (control): $0 \mathrm{mg} \mathrm{L}^{-1}$ IAA and $0 \mathrm{mg} \mathrm{L}^{-1}$ zeatin; $\mathrm{M}_{1}: 0.01 \mathrm{mg} \mathrm{L}^{-1} \mathrm{IAA}$ and $0.01 \mathrm{mg} \mathrm{L}^{-1}$ zeatin; $\mathrm{M}_{2}: 0.2 \mathrm{mg} \mathrm{L}^{-1} \mid \mathrm{AA}$ and $0.01 \mathrm{mg} \mathrm{L}^{-1}$ zeatin; $\mathrm{M}_{3}: 0.01 \mathrm{mg}$ $\mathrm{L}^{-1}$ IAA and $0.2 \mathrm{mg} \mathrm{L}^{-1}$ zeatin; $\mathrm{M}_{4}: 0.2 \mathrm{mg} \mathrm{L}^{-1} \mathrm{IAA}$ and $0.2 \mathrm{mg} \mathrm{L}^{-1}$ zeatin) and developmental stage. Each value represents the mean of the four accessions for each medium $\times$ stage combination.

\begin{tabular}{lccccc}
\hline & Globular & Heart & Torpedo & Cotyledonary & Mean \\
\hline $\mathrm{M}_{0}$ & $3.3 \mathrm{a}^{\mathrm{a}}$ & $26.7 \mathrm{~b}$ & $28.3 \mathrm{~b}$ & $36.6 \mathrm{~b}$ & $23.7 \mathrm{~b}$ \\
$\mathrm{M}_{1}$ & $3.3 \mathrm{a}$ & $16.7 \mathrm{~b}$ & $51.7 \mathrm{c}$ & $60.0 \mathrm{c}$ & $32.9 \mathrm{c}$ \\
$\mathrm{M}_{2}$ & $1.7 \mathrm{a}$ & $15.0 \mathrm{ab}$ & $40.0 \mathrm{bc}$ & $40.0 \mathrm{~b}$ & $24.2 \mathrm{~b}$ \\
$\mathrm{M}_{3}$ & $0.0 \mathrm{a}$ & $1.7 \mathrm{a}$ & $3.3 \mathrm{a}$ & $3.3 \mathrm{a}$ & $2.1 \mathrm{a}$ \\
$\mathrm{M}_{4}$ & $1.7 \mathrm{a}$ & $1.7 \mathrm{a}$ & $1.7 \mathrm{a}$ & $1.7 \mathrm{a}$ & $1.7 \mathrm{a}$ \\
\hline Mean & $2.0 \mathrm{~A}^{\mathrm{b}}$ & $12.3 \mathrm{~B}$ & $25.0 \mathrm{C}$ & $28.3 \mathrm{C}$ & \\
\hline
\end{tabular}

aDifferent lowercase letters within the same column indicates differences between in vitro media at $p<0.05$ (Fisher's least significant difference, LSD). 'Different capital letters within the row indicates differences between developmental stages at $p<0.05$ (Fisher's least significant difference, LSD).

capable of synthesizing substances required for their growth (autotrophic phase) from mineral salts and carbohydrates (Bhojwani and Razdan, 1996; Ramming, 1990), which explains the higher response observed in the advanced stages.

Considering the interaction between in vitro media composition and the embryo stage, low levels 10.01 $\mathrm{mg} \mathrm{L}^{-1}$ ) of both IAA and zeatin provided in the $\mathrm{M}_{1}$ formulation improved $(p<0.05)$ the results observed in our previously optimized medium $\left(\mathrm{M}_{0}\right)$. Thus, on average $M_{1}$ yielded the highest germination rates 132.9 $\%$ mean versus $23.7 \%$ in $M_{0}$ ) and at most stages, with the exception of the earliest embryos (Table 2). In comparison, the lack of these growth regulators in $\mathrm{M}_{0}$ or the combination of high IAA levels and low zeatin in $M_{2}$ provoked different responses. Thus, $M_{0}$ allowed the highest rates in heart embryos, although no differences were found in comparison to $M_{1}$ and $M_{2}$. However, $M_{0}$ efficiency barely increased in torpedo and cotyledonary embryos, being much lower than that of $M_{1}$ (Table 2). In the case of $\mathrm{M}_{2}$, germination rates of the earliest embryos were similar to those observed in $M_{1}$, although rates in the advanced stages were lower. These findings suggest that the lack of hormones may improve embryo germination at the earliest stages, while low levels of both IAA and zeatin provide better results in advanced immature embryos.

By contrast, $M_{3}$ and $M_{4}$ had the lowest germination rates, which was mainly due to abnormal plantlets or callus development. Thus, regardless of the embryo stage, the efficiency of these culture media was lower than $5 \%$ (Table 2). These findings and those observed in $\mathrm{M}_{2}$ indicate that high levels of zeatin dramatically decrease the survival rates of Capsicum embryos at all stages, while the detrimental effect of similar levels of IAA $\left(\mathrm{M}_{2}\right)$ is relatively low (compared to $M_{1}$ ) and only noticeable in cotyledonary embryos (Table 2). 
Exogenously supplied hormones are not required in many cases for embryo culture as embryos can be considered as plants with their own endogenous hormones (Monnier, 1996). When growth substances are added to the medium, they can modify the ontogenic pattern of embryos, including suppression of root growth, precocious leaf expansion, and longer thinner embryos, among others. Nevertheless, there are some cases, in which low concentrations of hormones in the medium have facilitated embryo culture.

It seems that in certain species, natural endosperms contain hormones and, therefore, the culture medium may be supplemented with hormones at a very low level that will reproduce the conditions of the in ovulo environment (Monnier, 1995). In this regard, auxins have a key regulatory function and are essential to axis establishment at the proembryo stage (Hamann, 2001; Haslam and Yeung, 2011). In fact, alteration of auxin transport may change embryo symmetry from bilateral to radial or provoke the abortion of shoot apical meristem (Liu et al., 1993; Ramesar-Fortner and Yeung, 2006). Thus, exogenous auxins at low concentrations have favored normal embryo growth, while higher levels have either proved inhibitory or favored unorganized callus growth. Moreover, cytokinins have usually resulted in growth inhibition, although low levels have been reported to stimulate embryo growth in some cases (Sharma et al., 1996).

The effect of the media composition on the response of the genotypes was quite similar to the findings for embryo stages. Thus, all the genotypes germinated at very low rates when cultured under $M_{3}$ or $M_{4}$ and, in fact, only California Wonder embryos cultured in $M_{3}$, showed efficiency rates slightly higher than $5 \%$. Therefore, our zeatin at relatively high levels should be not used to germinate any kind of embryos in peppers, although other authors have reported that levels of zeatin up to $0.2 \mathrm{mg} \mathrm{L}^{-1}$ may favor embryo growth, particularly at the earliest stages (Raghavan, 2006; Troncoso et al., 2003). By contrast, the rates observed in the media with low or zero levels of zeatin $\left(M_{0}, M_{1}\right.$ and $\left.M_{2}\right)$ were considerably higher (Table 3).

As observed at the embryo stage, $M_{1}$ also provided the highest germination rates in most genotypes

Table 3 - Culture efficiency (\% germination) of immature C. annuum embryos depending on the in vitro medium and accession utilized. Each value represents the mean of the four embryo stages for each medium $\times$ accession combination.

\begin{tabular}{lcccc}
\hline & California & Piquillo & Guindilla & Bola \\
\hline $\mathrm{M}_{0}$ & $20.0 \mathrm{~b}^{\mathrm{a}}$ & $15.0 \mathrm{~b}$ & $28.3 \mathrm{~d}$ & $31.7 \mathrm{~b}$ \\
$\mathrm{M}_{1}$ & $38.3 \mathrm{c}$ & $28.3 \mathrm{c}$ & $16.7 \mathrm{~cd}$ & $48.3 \mathrm{c}$ \\
$\mathrm{M}_{2}$ & $18.3 \mathrm{~b}$ & $20.0 \mathrm{bc}$ & $13.3 \mathrm{bc}$ & $45.0 \mathrm{bc}$ \\
$\mathrm{M}_{3}$ & $6.7 \mathrm{ab}$ & $0.0 \mathrm{a}$ & $0.0 \mathrm{a}$ & $1.7 \mathrm{a}$ \\
$\mathrm{M}_{4}$ & $0.0 \mathrm{a}$ & $1.7 \mathrm{a}$ & $1.7 \mathrm{ab}$ & $3.3 \mathrm{a}$ \\
\hline
\end{tabular}

aDifferent lowercase letters within the same column indicates differences between medium at $p<0.05$ (Fisher's least significant difference
(Table 3), although some examples of genotype $\times$ medium composition interaction were also found. Guindilla embryos were the only exception for which $M_{0}$ gave higher efficiency rates than $M_{1}$, suggesting that some genotypes might prefer the lack of IAA and zeatin rather than low/minimum levels of these regulators. Another example of this interaction can be found by comparing $\mathrm{M}_{0}$ and $\mathrm{M}_{2}$, as their rates were quite similar in California and Piquillo embryos, while $M_{0}$ provided higher rates than $M_{2}$ in Guindilla; the contrary being true in Bola (Table 3).

Although the effect of growth regulators in embryo culture is quite variable, depending on the species/genotype and embryo stage (Davey and Anthony, 2010; Sharma et al., 1996), we can conclude that, in the case of $C$. annuum immature embryos, a minimum content $\left(0.01 \mathrm{mg} \mathrm{L}^{-1}\right)$ of IAA and zeatin provides the best results. These findings are in agreement with the reports of other authors in several species such as barley, Phaseolus coccineus or Capsella bursa-pastoris, among others (Monnier, 1995; Raghavan, 2003; Umbeck and Norstog, 1979) and, therefore, medium $M_{1}$ was chosen to assess the effect of initial dark incubation on in vitro embryo germination.

\section{Effect of initial dark incubation}

The combination of $M_{1}$ and darkness $\left(M_{1}-D\right)$ in the first five days of embryo culture increased considerably embryo germination in comparison to the application of $M_{1}$ alone, suggesting a positive effect of this factor, although the highest differences were mainly found in the earliest stages (Figure 2). Thus, globular embryos showed a mean germination rate $>20 \%$ under $M_{1}-D$ combination, which was considerably higher than the mean rate of $M_{1}$ for these embryos, and even higher than the mean values reported by Manzur et al. (2013) in a wide collection of Capsicum spp. $M_{1}-D$ also provided higher germination rates in heart and torpedo

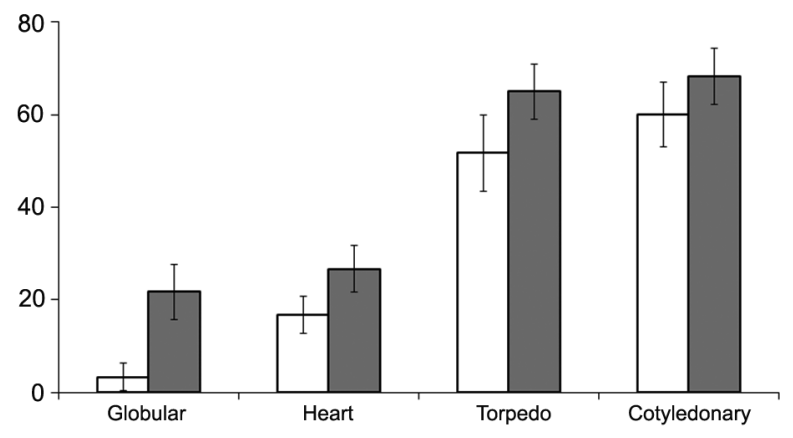

Figure 2 - Culture efficiency (\% germination, mean for all genotypes in each stage) of immature $C$. annuum embryos, under $\mathrm{M} 1$ medium (0.01 $\mathrm{mg} \mathrm{L}^{-1}$ IAA and $0.01 \mathrm{mg} \mathrm{L}^{-1}$ zeatin) with (grey) or without (white) 5 days of initial dark incubation. Lines on bars represent the mean \pm SE. 
stages than $M_{1}$, although differences were lower than those observed in globular embryos, particularly at the cotyledonary stage (Figure 2), which may be due to the strong autotrophic nature of these embryos, being less dependent on culture conditions. The action of cytokinins and auxins is light-dependent and they show remarkable degradation when exposed to the light, particularly auxins (George et al., 2008; Neumann et al., 2009). Probably, this fact explains the higher response to dark incubation observed in globular embryos, which are more dependent on media components, including growth regulators and, consequently, their degradation.

Considering the genotypes, a positive effect was found for $M_{1}-D$, which provided germination rates similar or higher than those of $M_{1}$ (Figure 3). $M_{1}$ plus initial cultivation under darkness improved the average efficiency in Guindilla, from $<20 \%$ to $>50 \%$, and to a lesser extent in Piquillo, from $<30 \%$ to $40 \%$, while this strategy did not improve mean rates in California and Bola embryos (Figure 3). In this regard, the first studies on this subject suggested that light was not critical for in vitro growth of immature embryos (Matsubara and Nakahira, 1965; Narayanaswamy and Norstog, 1964). However, more recent studies have revealed that a few days of incubation in darkness may favor subsequent chlorophyll formation in the immature embryos of, among others, barley, flax, and Aegilops $\times$ Hordeum and interspecific Allium hybrids (Razdan, 2003).

Comparing $M_{1}-D$ rates to the values recorded for $\mathrm{M}_{0}-\mathrm{M}_{4}$ (Tables 2 and 3) we can conclude that, in general, the former provides higher responses at any embryo stage and genotype, suggesting that low levels of IAA and zeatin $\left(0.01 \mathrm{mg} \mathrm{L}^{-1}\right)$ and relatively low levels of sucrose $\left(40 \mathrm{~g} \mathrm{~L}^{-1}\right)$ and MS salts $\left(2.2 \mathrm{~g} \mathrm{~L}^{-1}\right)$, combined with darkness during the first five days of embryo culture, is the best alternative for $C$. annuum embryos.

The protocol optimized in the present study can be directly applied to breeding programs to shorten the length of breeding cycles in Capsicum annuum as embryos can be germinated at very early stages, instead of using seeds from fully ripe fruits.

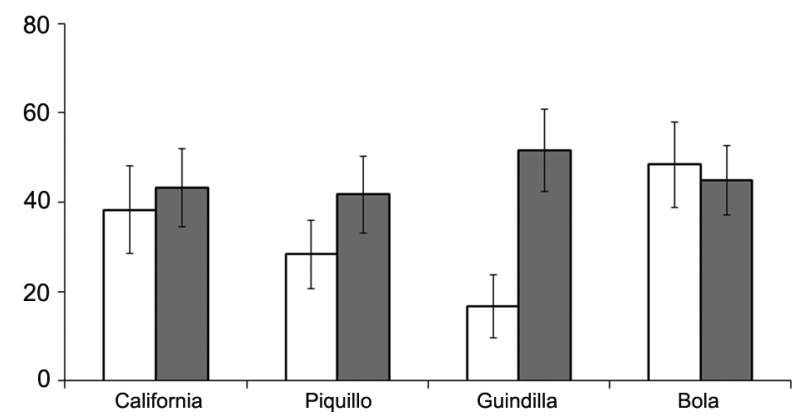

Figure 3 - Culture efficiency (\% germination) of immature $C$. annuum embryos, under M1 medium with (grey) or without (white) 5 days of initial dark incubation. Lines on bars represent the mean \pm SE.

\section{Acknowledgements}

Juan P. Manzur thanks Polytechnic University of Valencia for a research grant (2011-S2-4264, research staff training program, FPI). This work has been co-financed by INIA projects RTA2010-00038-C03-03 and RF2010-00025-00-00, and FEDER fundings. The authors thank NEIKER and the Regulatory Boards of D.O.P. Pimentón de Murcia and D.O.P. Pimiento del Piquillo de Lodosa for providing us with seeds of Guindilla de Ibarra, Bola and Piquillo.

\section{References}

Bhattarai, S.P.; De La Pena, R.C.; Midmore, D.J.; Palchamy, K. 2009. In vitro culture of immature seed for rapid generation advancement in tomato. Euphytica 167: 23-30.

Bhojwani, S.S.; Razdan, M.K. 1996. Plant Tissue Culture: Theory and Practice. Elsevier, Amsterdam, The Netherlands.

Blat, S.F.; Costa, C.P.; Vencovsky, R.; Sala, F.C. 2005. Inheritance of reaction to Leveillula taurica (Lev.) Arn. in Capsicum annuum L. Scientia Agricola 62: 40-44.

Crosby, K.M. 2008. Pepper. p. 221-248. In: Prohens, J.; Nuez, F., eds. Vegetables II. Springer, New York, NY, USA.

Davey, M.; Anthony, P. 2010. Plant Cell Culture: Essential Methods. Wiley-Blackwell, Chichester, West Sussex, UK.

FAOSTAT. 2011. FAOSTAT Agriculture Data. FAO, Rome, Italy. Available at: http://faostat.fao.org [Accessed Feb 1, 2013]

George, E.F.; Hall, M.A.; De Klerk, G.J. 2008. Plant Propagation by Tissue Culture. 3ed. Springer, Dordrecht, The Netherlands.

Guzzo, F.; Ceoldo, S.; Andreetta, F.; Levi, M. 2004. In vitro culture from mature seeds of Passiflora species. Scientia Agricola 61: 108-113.

Hamann, T. 2001. The role of auxin in apical-basal pattern formation during Arabidopsis embryogenesis. Journal of Plant Growth Regulation 20: 292-299.

Haslam, T.M.; Yeung, E.C. 2011. Zygotic embryo culture: an overview. p. 3-15. In: Thorpe, T.A.; Yeung, E.C., eds. Plant embryo culture: methods and protocols. Humana Press, New York, NY, USA.

Hossain, M.A.; Minami, M.; Nemoto, K. 2003. Immature embryo culture and interspecific hybridization between Capsicum annuum L. and C. frutescens L. via embryo rescue. Japan Journal of Tropical Agriculture 47: 9-16.

Kawashima, T.; Goldberg, R.B. 2009. The suspensor: not just suspending the embryo. Trends in Plant Science 15: 23-30.

Kothari, S.L.; Joshi, A.; Kachhwaha, S.; Ochoa-Alejo, N. 2010. Chili peppers: a review on tissue culture and transgenesis. Biotechnology Advances 28: 35-48.

Lotfi, M.; Alan, A.R.; Henning, M.J.; Jahn, M.M.; Earle, E.D. 2003. Production of haploid and doubled haploid plants of melon (Cucumis melo L.) for use in breeding for multiple virus resistance. Plant Cell Reports 21: 1121-1128.

Liu, C.M.; Xu, Z.H.; Chua, N.H. 1993. Auxin polar transport is essential for the establishment of bilateral symmetry during early plant embryogenesis. Plant Cell 5: 621-630. 
Machakova, I.; Zazimalova, E.; George, E.F. 2008. Plant growth regulators. I. Introduction: auxins, their analogues and inhibitors. p. 175-204. In: George, E.F.; Hall, M.A.; De Klerk, G.J., eds. Plant propagation by tissue culture. 3ed. Springer, Dordrecht, The Netherlands.

Manzur, J.P.; Herraiz, J.; Rodríguez-Burruezo, A.; Nuez, F. 2010. Evaluation of response to in vitro embryo rescue in Capsicum spp. p. 397-402. In: Prohens, J.; Rodríguez-Burruezo, A., eds. Advances in genetics and breeding of Capsicum and eggplant. Editorial Universitat Politècnica de València, Valencia, Spain.

Manzur, J.P.; Penella, C.; Rodríguez-Burruezo, A. 2013. Effect of the genotype, developmental stage and medium composition on the in vitro culture efficiency of immature zygotic embryos from genus Capsicum. Scientia Horticulturae 161: 181-187.

Matsubara, S.; Nakahira, R. 1965. Some factors affecting the growth of young embryo in vitro. Science Reports Kyoto Prefectural University (Natural Science, Live Science \& Welfare Science) Series A 16, 1.

Monnier, M. 1995. Culture of zygotic embryos. p. 117-153. In: Thorpe, T.A., ed. In vitro embryogenesis in plants. Kluwer Academic, Dordrecht, The Netherlands.

Moshkov, I.E.; Novikova, G.V.; Hall, M.A.; George, E.F. 2008. Plant growth regulators. III. Gibberellins, ethylene, abscisic acid, their analogues and inhibitors: miscellaneous compounds. p. 227-282. In: George, E.F.; Hall, M.A.; De Klerk, G.J., eds. Plant propagation by tissue culture. 3ed. Springer, Dordrecht, The Netherlands.

Narayanaswamy, S.; Norstog, K. 1964. Plant embryo culture. Botanical Review 30: 587-628.

Neumann, K.; Kumar, A.; Imani, J. 2009. Plant Cell and Tissue Culture: A Tool in Biotechnology Basics and Application. Springer, Berlin, Germany.

Raghavan, V. 2003. One hundred years of zygotic embryo culture investigations. Vitro Cellular \& Developmental Biology-Plant 39: 437-442.
Raghavan, V. 2006. Double Fertilization. Embryo and Endosperm Development in Flowering Plants. Springer, Berlin, Germany.

Ramesar-Fortner, N.S.; Yeung, E.C. 2006. Physiological influences in the development and function of the shoot apical meristem of microspore-derived embryos of Brassica napus cv. Topas. Canadian Journal of Botany 84: 371-383.

Ramming, D.W. 1990. The use of embryo culture in fruit breeding. HortScience 25: 339-342.

Razdan, M.K. 2003. Plant Tissue Culture. 2ed. Science Publishers, Enfield, NH, USA.

Sharma, D.R.; Kaur, R.; Kumar, K. 1996. Embryo rescue in plants-a review. Euphytica 89: 325-337.

Salamma, S.; Ravi Prasad Rao, B. 2013. In vitro embryo culture of Croton scabiosus Bedd. (Euphorbiaceae), an endemic plant of Southern Andhra Pradesh. IOSR Journal of Pharmacy and Biological Sciences 5: 108-114.

Sousa, J.A.; Maluf, W.R. 2003. Diallel analyses and estimation of genetic parameters of hot pepper (Capsicum chinense Jacq.). Scientia Agricola 60: 105-113.

Troncoso, A.; Cantos, M.; Liñán, J.; Troncoso, J.; Rapoport, H.F. 2003. In vitro development and germination of immature olive embryos. Journal of Horticultural Science \& Biotechnology 78 : 728-733.

Umbeck, P.F.; Norstog, K. 1979. Effects of abscisic acid and ammonium ion on morphogenesis of cultured barley embryos. Bulletin of the Torrey Botanical Club 106: 110-116.

Yoon, J.B.; Yang, D.C.; Do, J.W.; Park, H.G. 2006. Overcoming two post-fertilization genetic barriers in interspecific hybridization between Capsicum annuum and C. baccatum for introgression of anthracnose resistance. Breeding Science 56: 31-38. 